\title{
Article \\ Turn-to-Turn Fault Diagnosis on Three-Phase Power Transformer Using Hybrid Detection Algorithm
}

\author{
Chien-Hsun Liu, Willybrordus H. P. Muda and Cheng-Chien Kuo *D \\ Electrical Engineering Department, National Taiwan University of Science and Technology, Keelung Rd, \\ Da'an District, Taipei City 10607, Taiwan; u019366@taipower.com.tw (C.-H.L.); \\ M10707825@gapps.ntust.edu.tw (W.H.P.M.) \\ * Correspondence: cckuo@mail.ntust.edu.tw
}

Citation: Liu, C.-H.; Muda, W.H.P.; Kuo, C.-C. Turn-to-Turn Fault Diagnosis on Three-Phase Power Transformer Using Hybrid Detection Algorithm. Appl. Sci. 2021, 11, 2608. https://doi.org/10.3390/app11062608

Academic Editor: Gaetano Zizzo

Received: 21 February 2021

Accepted: 9 March 2021

Published: 15 March 2021

Publisher's Note: MDPI stays neutral with regard to jurisdictional claims in published maps and institutional affiliations.

Copyright: (C) 2021 by the authors Licensee MDPI, Basel, Switzerland. This article is an open access article distributed under the terms and conditions of the Creative Commons Attribution (CC BY) license (https:// creativecommons.org/licenses/by/ $4.0 /)$.

\begin{abstract}
A power transformer (PT) in power generation or transmission is critical to maintaining electrical continuity. Fault detection on a PT is needed, especially of incipient faults, which are often caused by a turn-to-turn fault (TTF) before it develops into a more severe fault. We use a hybrid algorithm between conventional and modern techniques to detect a developing fault in a PT. The current response signals from a negative sequence current directional algorithm, extended park vector algorithm (EPVA), differential negative sequence current, and EPVA-fuzzy system are combined to distinguish the possibility of a TTF. The subalgorithms are combined using a hybrid detection algorithm to distinguish the faults. The model is a $10 \mathrm{MVA}$, three-phase PT with $\Delta-\mathrm{Y}$ configuration $150 / 300 \mathrm{kV}$, simulated using MATLAB Simulink software. The results show that by combining the subalgorithms, several limitations are distinguished within the TTF with a slight increase in accuracy.
\end{abstract}

Keywords: power transformer protection; turn-to-turn fault; negative sequence current

\section{Introduction}

Power transformers (PTs) are essential to maintain the stable operation of a power grid. There is a massive number of transformers in service, and internal faults occur in the long-term ageing process [1]. However, conducting maintenance with system outage or assessment of the transformer means considering the expenditure and time due to production loss. Energize levels at $765 \mathrm{kV}$, and even $400 \mathrm{kV}$, can generate inrush currents which can cause internal PT damage. There are several protection schemes required for effective discrimination between an internal fault and inrush [2].

The faulty components need to be fixed quickly as they can cause severe damage, loss, and power stability problems. Outages resulting from a fault in PTs cause significant revenue loss and affect consumer service. Therefore, online PT monitoring is needed to avoid these outages. If the faults are not detected, they will develop into more severe faults. Thus, detection of inter-turn faults is a concern in power systems [3,4]. The result of a transformer failure survey, based on the investigation of 750 massive transformer failures from 1996 to 2010, confirmed the importance of short-circuit strength as almost half of the failures were correlated to winding and the insulating system [5,6]. Accounting for transformer winding connections is required to apply differential protection principles to PTs. Concerning transformers of standard winding connections, these protection rules are commonly referred to as ratio matching, vector group compensation, and zero-sequence removal. The standard protection method is the differential protection current between the line-to-line. The protection method is used for protecting power transformers of $10 \mathrm{MVA}$ and above [7].

However, the differential protection provides accurate results in most of the fault cases, and it suffers from the problem of accidental tripping during external events such as magnetizing inrush conditions [8]. The percentage differential scheme is used to restrain 
the second harmonic component, and sometimes the fifth harmonic component, to avoid accidental tripping against magnetizing inrush conditions [2,9]. Another problem when using conventional differential protection is the detection of the low-level winding turn-toturn fault (TTF). If this fault happens, the terminal current is relatively unchanged, and the circulating current in the short turn area will increase and be dangerous. This protection only detects if the differential current exceeds $20 \%$ to $25 \%$ of the rated current [10].

Many methods are used to detect TTFs in PT windings. Solutions include optimization of the PT's estimation parameter problem [11-14] and an artificial base using neural networks $[15,16]$ to detect TTFs. The optimization technique searches for the optimal PT parameter. Ouyang et al. [17] applied the parameter identification of a transformer based on the PSO algorithm using port data. In this research, the internal transformer fault can be determined according to the model reference adaptive principle. The fitness function consists of the two models' response performance, and its corresponding circuit parameters are calculated using the PSO algorithm. The PSO algorithm is used to obtain the optimum value from the model's equivalent parameters and converge. The optimal parameter obtained from the optimization process is the equivalent parameter in the model to be identified. However, using the optimization method has a higher computational burden than using the analog signal-based method (terminal current signal).

The negative sequence current scheme could be an alternative for fault detection and distinguish between an internal (TTF) and an external fault. The negative sequence current is a simple and efficient protection technique to detect minor internal TTFs in PTs. According to [10] and [7], the negative sequence detects TTFs involving 1\% transformer winding. However, the negative sequence current algorithm cannot distinguish when an external and internal fault occur simultaneously. The extended park vector algorithm (EPVA) method can detect and distinguish turn-to-turn winding insulation failures from magnetizing inrush current transients. The EPVA also overcomes the limitation of the negative sequence current algorithm. The EPVA is not affected by the external fault and can detect the TTF accurately.

Fuzzy logic was developed to detect TTFs in a transformer. Here, fuzzy logic is employed to monitor the transformer's condition and improve the protection system's performance. Using fuzzy logic overcomes the traditional PT differential scheme's limitations by detecting a low-level TTF. The fuzzy-based technique is simple, robust, and able to detect incipient faults at an early stage [4], and shows a fast and accurate trip operation [18]. The fuzzy algorithm also improves the accuracy of the diagnosis and the efficiency of transformer maintenance [19]. A combination technique using fuzzy logic and Clark's transform was used to improve the differential protection performance [20]. A TTF may occur even if no current is flowing on one side of the transformer during energization. With no current flowing in the secondary windings of the transformer, negative-sequence current-based algorithms become insensitive.

This paper discusses a voting algorithm that is a combination of several protection algorithms and used to make the right decision for fault detection. The algorithms used are the negative-sequence directional algorithm, EPVA, differential negative-sequence algorithm, and the fuzzy Mamdani conventional protective algorithm. According to the simulation, each algorithm detects whether the fault belongs to an internal or external fault. The results from each algorithm were collected, and we calculated how many possibilities of internal fault and external fault happened.

Section 2 of this paper introduces the turn-to-turn equivalent circuit and transformer configuration. Section 3 discusses the purpose and method to detect and distinguish PT faults. Section 4 shows the results and discussion of the TTF simulation in a PT for a $1 \%$ turn fault, followed by an external fault. Section 5 concludes the research.

\section{Hybrid Algorithm in TTF Diagnosis System}

The hybrid algorithm's aim is to create a fault detection system in a PT, especially for TTF recognition. The algorithm uses a terminal current as an input and generates 
a condition state of a PT regarding the TTF. The algorithm's output can be used as a supporting tool to monitor a TTF inside a PT while not connected to the protection breaker of the PT. In this research, we simulated the proposed algorithm into a PT model using MATLAB Simulink. This algorithm combined and obtained results from the subalgorithms (Figure 1b) to obtain the PT's final condition fault status.

\begin{tabular}{|c|c|c|c|}
\hline \multicolumn{4}{|l|}{ Methode: } \\
\hline 1. Conventional Diff Protection & Fault & \multicolumn{2}{|c|}{ Normal } \\
\hline 2. Diff Negative Squence Protection & Internal Fault & \multicolumn{2}{|c|}{ Non-Internal Fault } \\
\hline $\begin{array}{l}\text { 3. Extended Park Vector Algorithm } \\
\text { (EPVA) Protection }\end{array}$ & Internal Fault & \multicolumn{2}{|c|}{ Non-Internal Fault } \\
\hline $\begin{array}{l}\text { 4. Negative Sequence Directional } \\
\text { Algorithm Protection }\end{array}$ & Internal Fault & External Fault & Normal \\
\hline 5. Fuzzy Protection & Internal Fault & External Fault & Normal \\
\hline $\begin{array}{l}\text { HY B R I D COMBINATION } \\
\text { RESULT }\end{array}$ & Internal Fault & External Fault & Normal \\
\hline
\end{tabular}

(a)

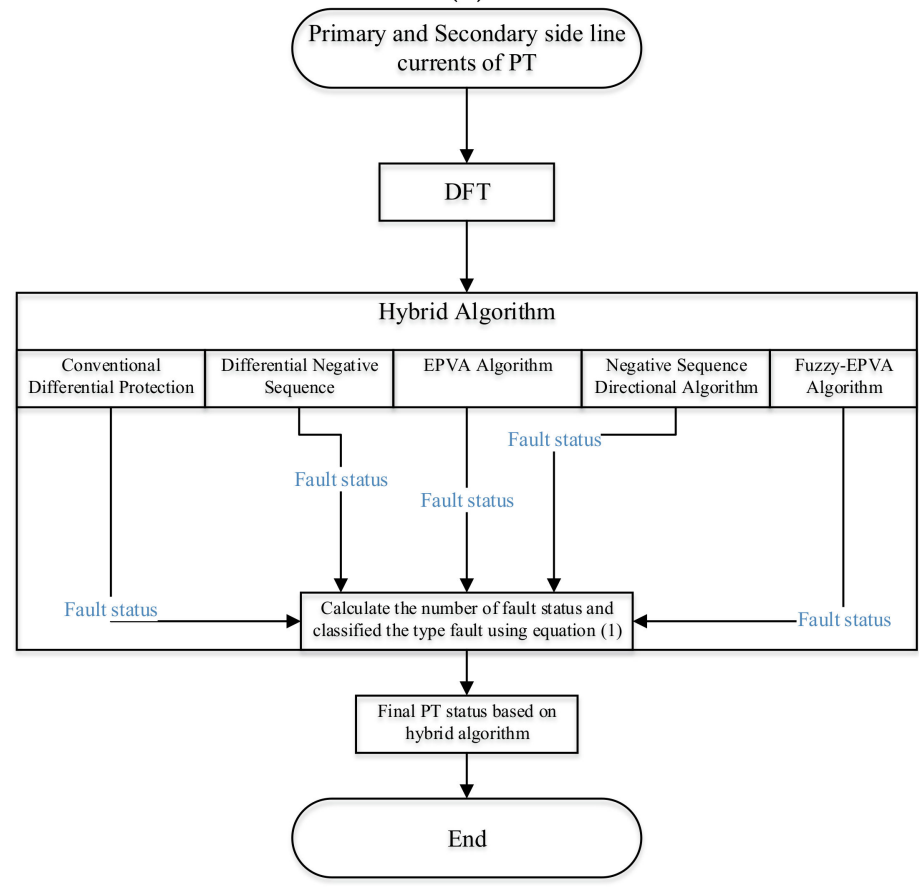

(b)

Figure 1. (a) User interface from the hybrid detection algorithm; (b) the flowchart of the hybrid algorithm.

The sub algorithms are the conventional differential protection, negative-sequence directional algorithm, EPVA, negative differential sequence, and fuzzy EPVA algorithm. Each has a different role in PT fault diagnosis and generates different decisions (internal fault, external fault, and normal condition).

The conventional differential protection can detect fault if the difference value of the phase current between primary and secondary winding is higher than the threshold value. This protection only detects a fault or normal state and is incapable of distinguishing the type of fault, either internal or external. The negative sequence directional algorithm and fuzzy logic detect three states of a PT's condition. Both can detect internal faults, which, in this case, was caused by a TTF. 
The differential negative sequence and EPVA only detect internal and noninternal fault states. The hybrid algorithm protection decides the internal, external, or normal conditions based on each sub algorithm's result. The hybrid algorithm chooses the most detected condition, which is generated by the sub algorithms.

This method is used to distinguish the weaknesses for each sub algorithm. The conventional differential protection is unable to distinguish if a fault in the transformer, either an internal or external fault, occurs. This algorithm is not sensitive enough to detect low-level TTFs inside the transformer [3]. The negative-sequence directional algorithm can detect a TTF when external and internal faults occur simultaneously [10]. The differential negative sequence and EPVA only detect the internal fault and non-internal fault conditions. When there is an external fault, the algorithm detects a non-internal fault, which is the same as in the normal condition. The internal fault will decide if there are more than or equal to two internal fault states $\left(\mathrm{n}_{\mathrm{if}}\right)$, declared by the sub algorithm. This rule also applies to the external fault state $\left(\mathrm{n}_{\mathrm{ef}}\right)$. The external fault will declare if there are more than two external fault statuses. A noninternal fault in the differential negative sequence protection and EPVA could indicate an external fault or a normal condition. A normal condition is decided if all sub algorithms declare a normal condition and a non-internal fault condition for the differential negative sequence protection and EPVA. The rule for the hybrid detection algorithm is expressed in Equation (1). Principally, the hybrid detection algorithm declares a transformer condition based on sub algorithm results. The interface from the hybrid algorithm detection is shown in Figure 1a.

$$
\text { PT Fault Condition }=\left\{\begin{array}{c}
\text { Internal fault, } \mathrm{n}_{\mathrm{if}} \geq 2 \\
\text { External fault, } \mathrm{n}_{\mathrm{ef}} \geq 2 \\
\text { Normal, } \mathrm{n}_{\mathrm{fault}}=0
\end{array}\right.
$$

\subsection{Conventional Differential Protection}

The first sub algorithm is the conventional differential protection. This protection is a conventional method, which measures the differential current between the primary and secondary side for each phase. This protection is unit-type for a specified zone or piece of equipment. It is only in the case of faults to the zone that the differential current (the difference between input and output currents) is high [21]. Differential protection schemes are mainly used for protection against phase-to-phase faults and phase-to-earth faults. Typically, the operating coil carries no current as they are balanced on both of the PT'S sides. When the fault occurs in the PT windings, the balance is disturbed. The differential relay's operating coils carry a current corresponding to the different current among the transformers' two sides. Thus, the relay trips the main circuit breakers on both sides of the PT. The first sub algorithm is mainly used to distinguish between the normal and external fault conditions in a PT.

\subsection{Negative Sequence Directional Algorithm}

The second sub algorithm is the negative-sequence directional algorithm. This algorithm uses an asymmetrical component from a 3-phase current principle to detect a fault, especially a TTF. When there is a fault, either internal or external, the current phase will not be symmetric or phasors become unbalanced. An unbalanced phasor generates positive $\left(\mathrm{I}_{1}\right)$, negative $\left(\mathrm{I}_{2}\right)$, and zero $\left(\mathrm{I}_{0}\right)$ sequence components, which are members of the balance set. The 3-phase currents from the primary and secondary side are extracted by the discrete Fourier transform algorithm. The symmetrical components determined by applying the Fortescue transformation are presented in Equation (3). The unbalance current can be expressed as the sum of their components, as shown in Equation (2).

$$
\begin{array}{lc}
\mathrm{I}_{\mathrm{a}}= & \mathrm{I}_{0}+\mathrm{I}_{1}+\mathrm{I}_{2} \\
\mathrm{I}_{\mathrm{b}}= & \mathrm{I}_{0}+\mathrm{a}^{2} \mathrm{I}_{1}+\mathrm{aI}_{2} \\
\mathrm{I}_{\mathrm{c}}= & \mathrm{I}_{0}+\mathrm{aI}_{1}+\mathrm{a}^{2} \mathrm{I}_{2}
\end{array}
$$


A phase rotation operator (a) is defined to rotate a phasor vector. Phases are rotated forward by $120^{\circ}$. Conversely, the phase currents' sequence components can be written as Equation (2) [22].

$$
\begin{aligned}
& \mathrm{I}_{0}=c \frac{1}{3}\left(\mathrm{I}_{\mathrm{a}}+\mathrm{I}_{\mathrm{b}}+\mathrm{I}_{\mathrm{c}}\right) \\
& \mathrm{I}_{1}=\frac{1}{3}\left(\mathrm{I}_{\mathrm{a}}+\mathrm{aI}_{\mathrm{b}}+\mathrm{a}^{2} \mathrm{I}_{\mathrm{c}}\right) \\
& \mathrm{I}_{2}=\frac{1}{3}\left(\mathrm{I}_{\mathrm{a}}+\mathrm{a}^{2} \mathrm{I}_{\mathrm{b}}+\mathrm{aI}_{\mathrm{c}}\right)
\end{aligned}
$$

The negative sequence current $\left(\mathrm{I}_{2}\right)$ will increase if there is an unbalanced phasor or fault. If the value exceeds a predefined threshold with a typical default of $4 \%$ of the rated current, the angle between them is compared. When a different angle $\left(\boldsymbol{\Delta}_{\mathrm{\phi} 2 \mathrm{TH}}\right)$ is between a predefined directional limit, typically from $\pm 60^{\circ}$ to $\pm 85^{\circ}$ [10], the internal fault is detected. Otherwise, it is an external fault (Figure 2). The second subalgorithm is used for distinguishing between internal and external faults and normal condition.

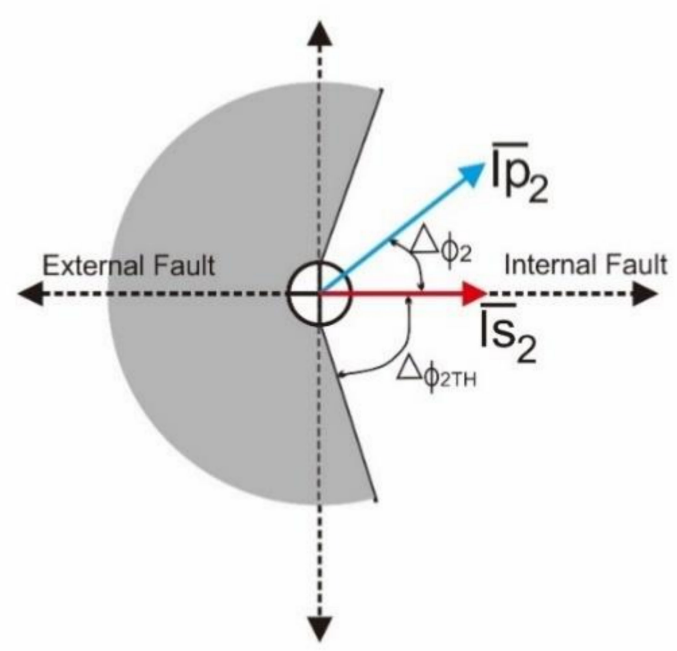

Figure 2. The negative sequence directional degree classification.

\subsection{EPVA}

The third sub algorithm is the EPVA, which is based on a space vector transformation. A space vector transformation describes the three-phase systems' behavior and was applied to the PT's differential protection. The EPVA is based on the spectral analysis of the differential current Park's vector modulus AC level.

The three-phase quantities are changed into a synchronous rotating reference frame using the $\mathrm{ABC}-\mathrm{DQ}$ transformation [23]. The direct and quadrature current from Park's vector components $\left(\mathrm{I}_{\mathrm{D}}, \mathrm{I}_{\mathrm{Q}}\right)$ are obtained by the Park transformation using Equation (5) [10], where $i_{d a}, i_{d b}$, and $i_{d c}$ denote the differential current for each phase. The current is used as inputs for calculating $\mathrm{I}_{\mathrm{D}}$ and $\mathrm{I}_{\mathrm{Q}}$.

$$
\begin{gathered}
{\left[\begin{array}{l}
\mathrm{i}_{\mathrm{dA}} \\
\mathrm{i}_{\mathrm{dB}} \\
\mathrm{i}_{\mathrm{dC}}
\end{array}\right]=\left[\begin{array}{l}
\mathrm{i}_{\mathrm{LA}} \\
\mathrm{i}_{\mathrm{LB}} \\
\mathrm{i}_{\mathrm{LC}}
\end{array}\right]+\frac{\mathrm{N}_{\mathrm{S}}}{\mathrm{N}_{\mathrm{p}}}\left[\begin{array}{ccc}
1 & 0 & -1 \\
-1 & 1 & 0 \\
0 & -1 & 1
\end{array}\right]\left[\begin{array}{l}
\mathrm{i}_{\mathrm{La}} \\
\mathrm{i}_{\mathrm{Lb}} \\
\mathrm{i}_{\mathrm{Lc}}
\end{array}\right]} \\
{\left[\begin{array}{c}
\mathrm{I}_{\mathrm{D}} \\
\mathrm{I}_{\mathrm{Q}}
\end{array}\right]=\left[\begin{array}{ccc}
\sqrt{\frac{2}{3}} & -\sqrt{\frac{1}{6}} & -\sqrt{\frac{1}{6}} \\
0 & \sqrt{\frac{1}{2}} & -\sqrt{\frac{1}{2}}
\end{array}\right]\left[\begin{array}{c}
\mathrm{i}_{\mathrm{dA}} \\
\mathrm{i}_{\mathrm{dB}} \\
\mathrm{i}_{\mathrm{dC}}
\end{array}\right]} \\
\mathrm{i}_{\mathrm{EPVA}}=\left|\mathrm{i}_{\mathrm{D}}+\mathrm{i}_{\mathrm{Q}}\right|=\sqrt{\mathrm{i}_{\mathrm{D}}^{2}+\mathrm{i}_{\mathrm{Q}}^{2}}
\end{gathered}
$$

The DC level $i_{\text {EPVA }}$ is obtained using Equation (6). The EPVA current is proportional to the balanced three-phase current system (conditions A and B in Figure 3). An incipient 
winding fault leads to an increase in the magnitude of the differential current of the affected phase compared with a healthy situation, which results in an unbalanced three-phase currents system (condition C in Figure 3). Under these conditions, the differential current Park's vector modulus contains a DC level and an AC level at twice the supply frequency $(2 \mathrm{f})[24,25]$. The subalgorithm EPVA technique in this research is used to distinguish between internal fault and normal condition.

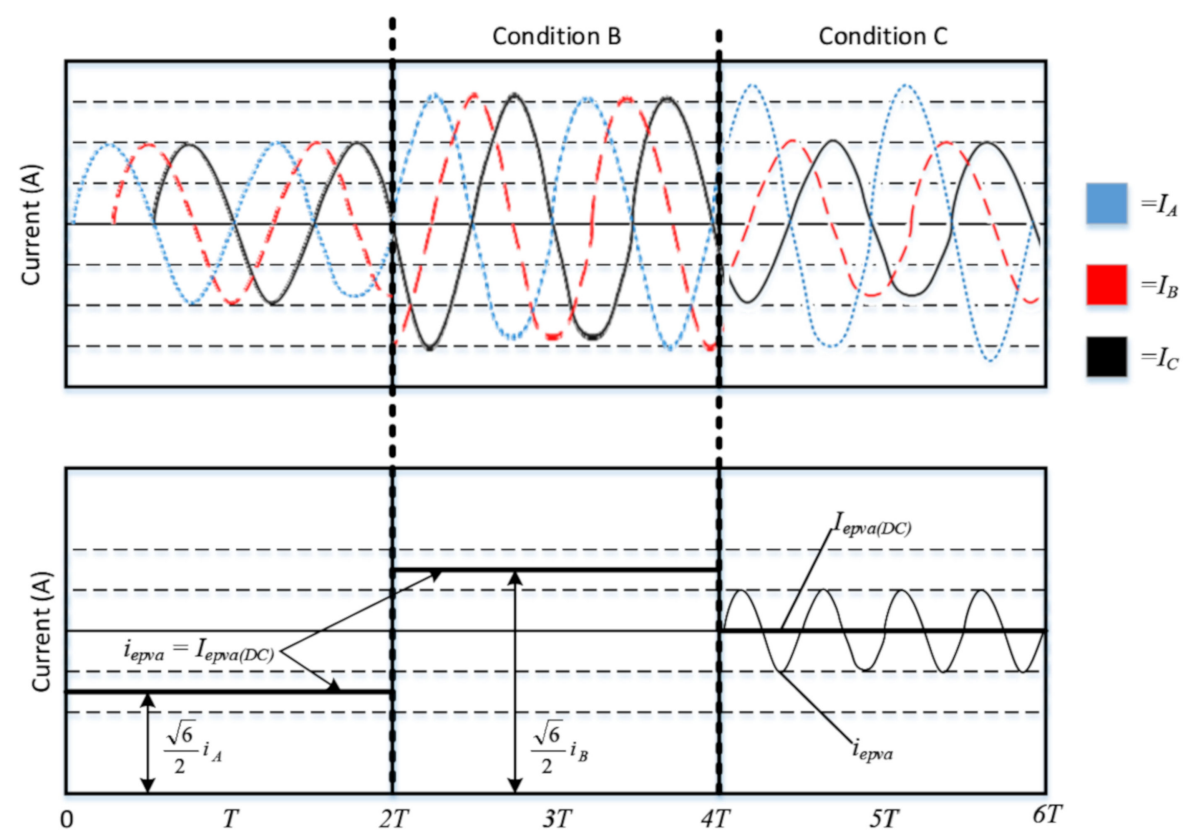

Figure 3. The EPVA principle in TTF detection [25].

\subsection{Differential Negative-Sequence Protection}

The fourth sub algorithm is the differential negative sequence protection. The application of the negative-sequence algorithm for the protection of PTs has attracted great attention in the last years and several variants of the method have been proposed. This algorithm measures the different values of the negative-sequence current over a finite time. During an internal fault, the negative current sequence generates a current and the differential current (3) increases so the differential current and negative-sequence current can fuse. This algorithm uses the differential current (refer to Equation (4)) to obtain a negative-sequence component using Equation (3). The inputs from Equation (3) are substituted by the differential current value for each phase. The differential negative sequence can be expressed as Equation (7).

$$
\mathrm{I}_{\mathrm{d} 2}=\frac{1}{2}\left(\mathrm{I}_{\mathrm{da}}+\mathrm{a}^{2} \mathrm{I}_{\mathrm{db}}+\mathrm{aI}_{\mathrm{dc}}\right)
$$

\subsection{Fuzzy EPVA}

The fuzzy inference system is a process that works using a parallel method. There is no data loss during the process because of this property. The fault detection generates more precise results than conventional relaying techniques [18]. The fuzzy inference collects and processes data, mapping from a given input to an output, using fuzzy logic. All the rules are evaluated in parallel using fuzzy reasoning using the differential current and EPVA current as inputs to the fuzzy system (Figure 4). The two inputs are processed inside the fuzzy logic system to generate a crisp value or output score for each fault (internal and external). This scoring system can indicate which fault occurred inside a PT. 


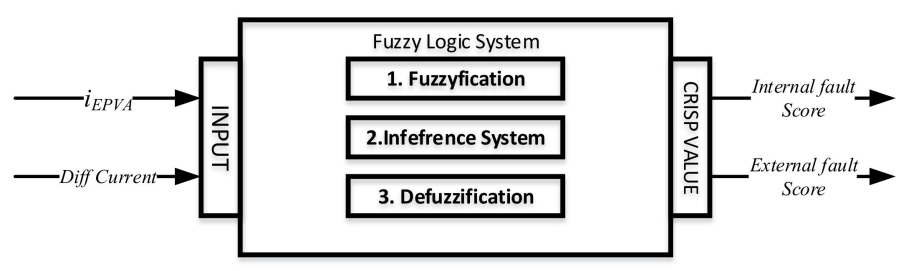

Figure 4. The fuzzy logic system flow.

Inside the fuzzy logic system are three parts: fuzzification, inference system, and defuzzification. Fuzzification is used to convert the measured quantities from the process (voltages, velocities, temperatures, etc.) into fuzzy sets used by the inference stage. Each input, either the EPVA current or the differential current, uses a trapezoidal form as its function with three levels (low, medium, and high). The membership function for the output value (internal and external fault) uses a Gaussian bell function with three values: incipient fault (IF), medium fault (MF), and severe fault (SF). The inference system is a process to determine each rule's degree of firing in the rule base. The inference stage's second function is to determine the degree to which each rule's recommendation is weighted when arriving at the final decision, and to decide an implied fuzzy set corresponding to each rule. The number of fuzzy inference rules for the proposed system is 15, as shown in Figure 5. The defuzzification stage converts the collection of recommendations of the rules into a crisp output. The centroid is used as a defuzzification stage in Equation (8) [26], where DV signifies defuzzification value; and $\mathrm{xi}$, and $\mu(\mathrm{xi})$ are inputs and the membership function value, respectively. If the DV from the internal fault is greater than the external fault, the decision is generated as an internal fault. However, if the DV from the internal fault is less than an external fault, the decision is generated as an external fault.

$$
D V=\frac{\sum_{i=0}^{n} x_{i} \mu\left(x_{i}\right)}{\sum_{i=0}^{n} \mu\left(x_{i}\right)}
$$

\begin{tabular}{|c|l|l|l|l|l|}
\hline \multicolumn{5}{|c|}{ INTERNAL FAULT } \\
\cline { 3 - 7 } \multicolumn{2}{|c|}{} & \multicolumn{4}{c|}{ Differential Current } \\
\cline { 3 - 7 } & None & Low & Medium & High \\
\hline \multirow{3}{*}{ EPVA } & None & & & & \\
\cline { 2 - 6 } & Low & IF & IF & MF & \\
\cline { 2 - 6 } & Medium & SF & MF & SF & SF \\
\cline { 2 - 6 } & High & SF & SF & SF & SF \\
\hline
\end{tabular}

(a) Fuzzy rules for Internal fault (TTF)

\begin{tabular}{|c|l|l|l|l|l|}
\hline \multicolumn{5}{|c|}{ EXTERNAL FAULT } \\
\cline { 3 - 6 } \multicolumn{2}{|c|}{} & \multicolumn{4}{c|}{ Differential Current } \\
\cline { 3 - 6 } & None & Low & Medium & High \\
\hline \multirow{3}{*}{ EPVA } & None & & IF & MF & SF \\
\cline { 2 - 6 } & Low & & & IF & MF \\
\cline { 2 - 6 } & Medium & & & IF & MF \\
\cline { 2 - 6 } & High & & & IF & SF \\
\hline
\end{tabular}

(b) Fuzzy rules for external fault.

Figure 5. Fuzzy rules for internal (a) and external fault (b) classification.

\section{Simulation Setup}

We developed a turn-to-turn fault simulation on a $10 \mathrm{MVA}$, three-phase, power transformer with $\Delta-Y$ configuration of $150 / 300 \mathrm{kV}$. For the simulation, we used the SIMSCAPE 
module on MATLAB. When developing the turn-to-turn fault simulation, the shorting resistor was used to simulate the short turn in a primary winding on phase A. The shortcircuited turns act as an autotransformer load on the winding, where $R_{s h}$ represents the fault impedance [3].

The configuration model is shown in Figure 6, and the equivalent short circuit is shown in Figure 7. The distribution of the magnetic flux is fundamentally altered by the transformer with an internal turn-to-turn fault. An exciting current is required to produce the magnetic flux in the core. The exciting current flows in the primary winding, where it establishes an altering flux in the magnetic circuit. When an internal turn-to-turn fault occurs, the situation is more complex [22].

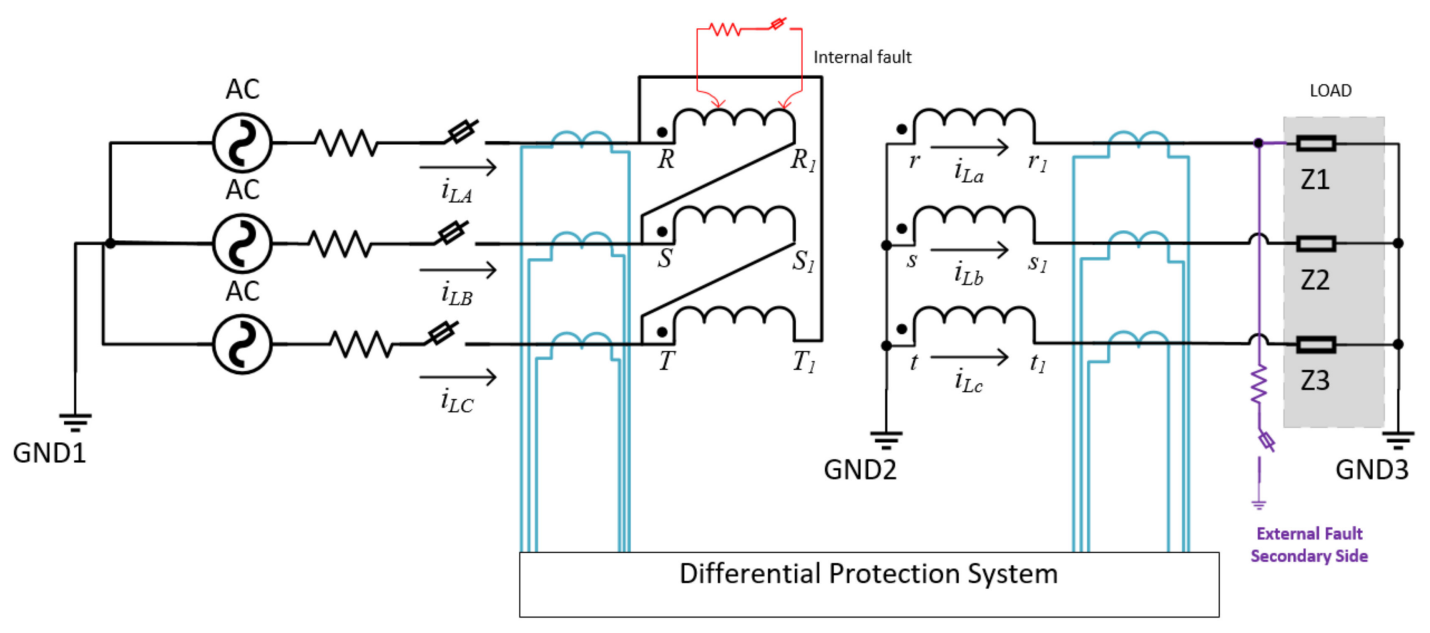

Figure 6. The TTF in 3 phase power transformer model.

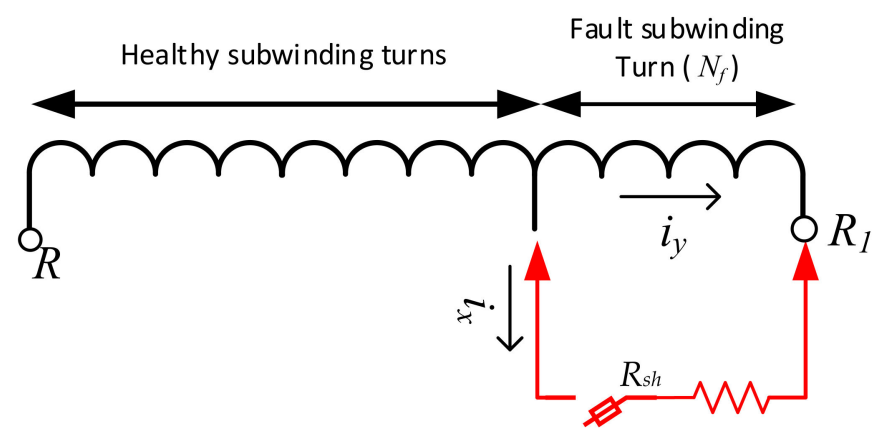

Figure 7. The equivalent circuit for the short turn in primary winding phase A.

\section{Simulation and Comparative Analysis}

The following figures show the simulation results regarding the turn fault, external fault, and normal scheme. Differential current and line current signals were collected from the simulation data. Those signals became the input for the sub algorithms, while the hybrid detection algorithm decided the final condition based on the sub algorithms results.

\subsection{Turn-to-Turn Fault Scheme}

In this scheme, the fault happened at $t=3 \mathrm{~s}$. The number of short turns on the primary winding varied between $0.8 \%$ and $16 \%$ from the total winding turn. The turnto-turn fault did not make a difference in the terminal current of PT or voltage while in primary or secondary current (see Figure 8). Therefore, the conventional differential protection algorithm failed to detect this kind of fault. In the early stage of the short turn level, the conventional algorithm was incapable of detecting the fault because the 
differential current was too small and did not exceed the predefined threshold value. The conventional algorithm was also unable to distinguish whether the fault caused by an internal or external fault.
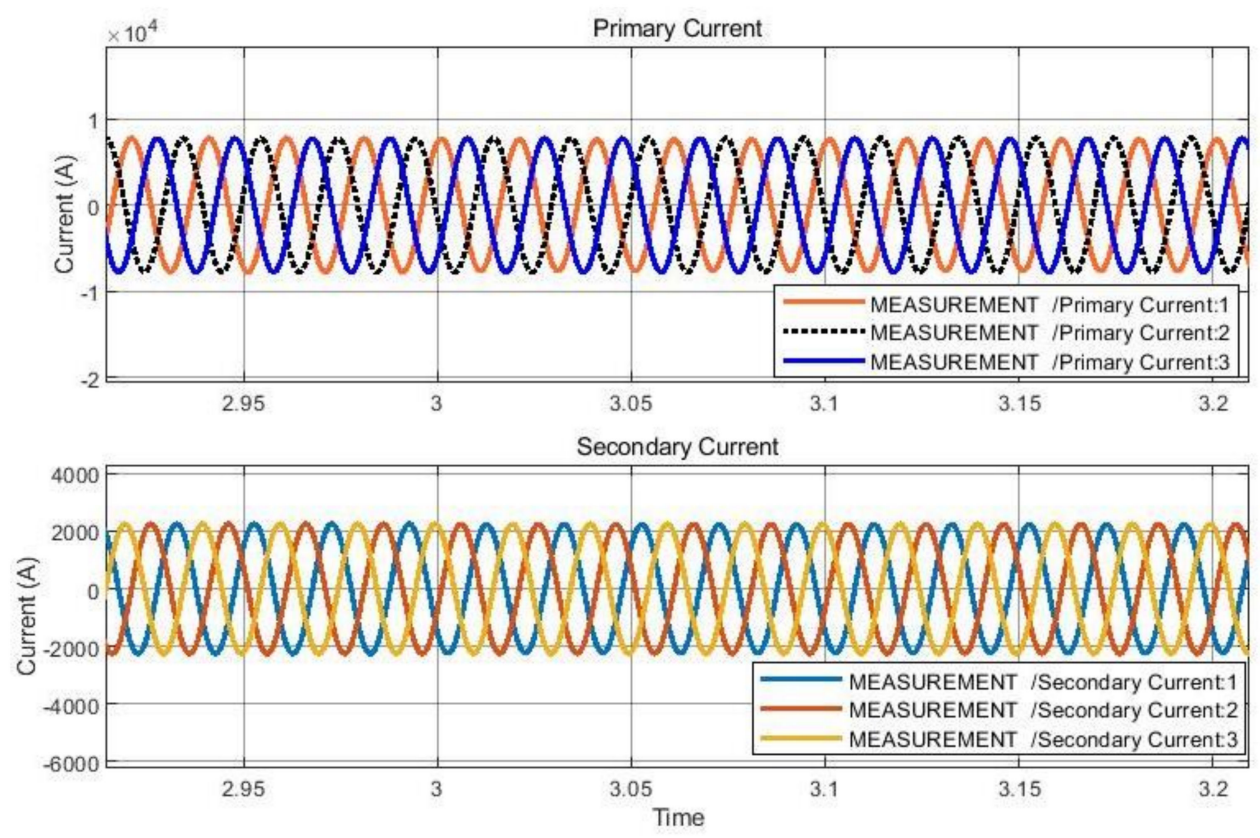

Figure 8. Fundamental component under $2.4 \%$ TTF condition.

The negative-sequence directional algorithm can give a correct decision when the TTF occurs. When the turn-to-turn fault occurred, the negative -sequence current in the primary side (Ip2) increased significantly and increased slightly on the secondary side (Is2) (see Figure 9). The phase difference between the negative sequence current in the primary and secondary side decreased to between $+60^{\circ}$ and $+85^{\circ}$ like in Figure 10. So that the negative sequence directional algorithm declares internal fault. EPVA current $\left(i_{\text {epva }}\right)$ rose to $104.8 \mathrm{~A}$ (see Figure 11), and the differential negative sequence current increased to $85.55 \mathrm{~A}$ (see Figure 12). The result for the EPVA and differential negative sequence algorithm showed the correct result to decide the fault. However, these algorithms cannot distinguish between normal and external fault conditions discussed in the external scheme.

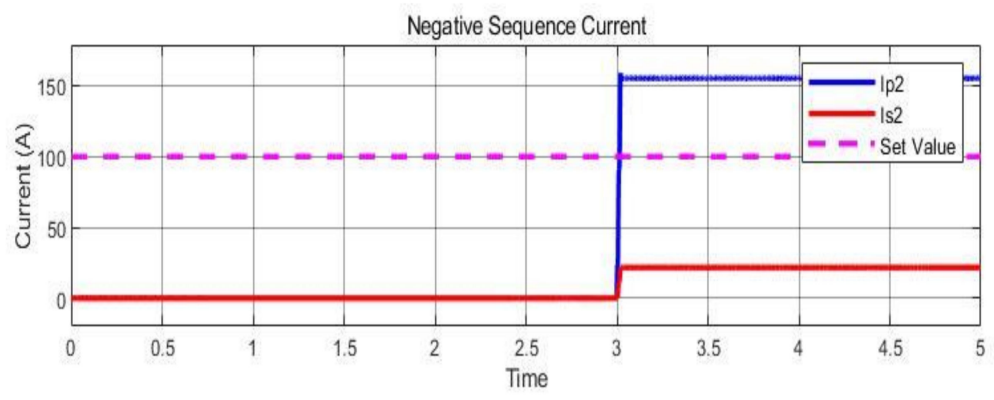

Figure 9. The negative sequence current from the primary and secondary side under $2.4 \%$ TTF condition. 


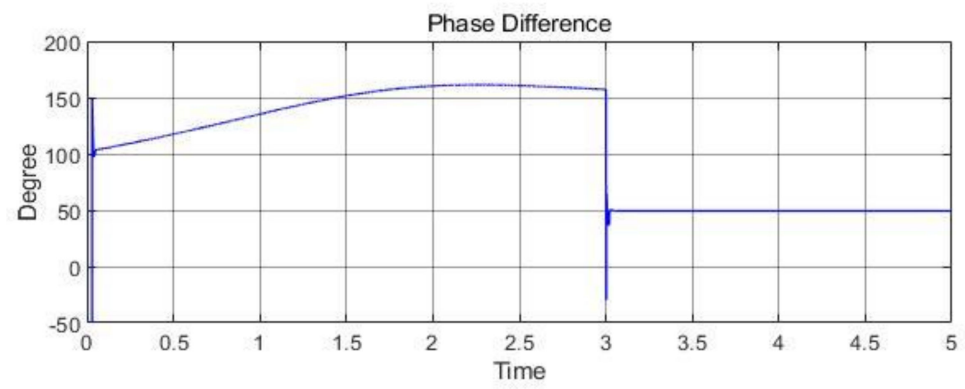

Figure 10. The phase difference between Ip2 and Is2 under $2.4 \%$ TTF condition.

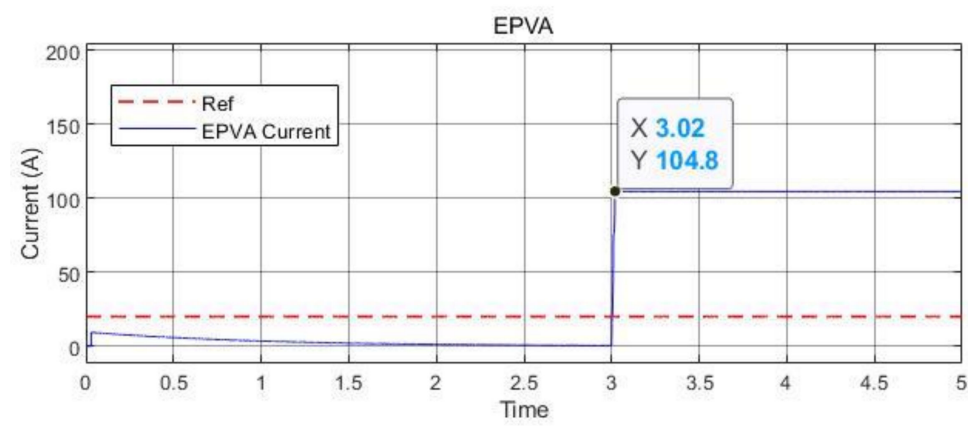

Figure 11. EPVA current $\left(i_{\text {epva }}\right)$ under $2.4 \%$ TTF condition.

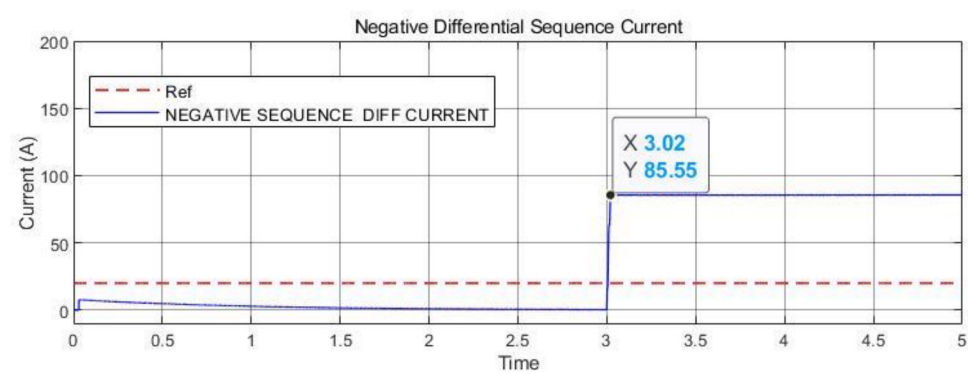

Figure 12. The differential negative sequence current under $2.4 \%$ TTF condition.

For comparison, the result table shows that in the early stage of the TTF, with a 0.8 and $1.6 \%$ short turns level, the EPVA and differential negative sequence current were more sensitive to detecting the fault. The fuzzy algorithm showed that the internal fault crisp value was more significant than the external fault (see Figure 13). The internal fault crisp value was 1559, and the external fault crisp value was 53.42. Based on the result, the fuzzy algorithm declared an internal fault state at the 1.6\% turns-to-turns short level.

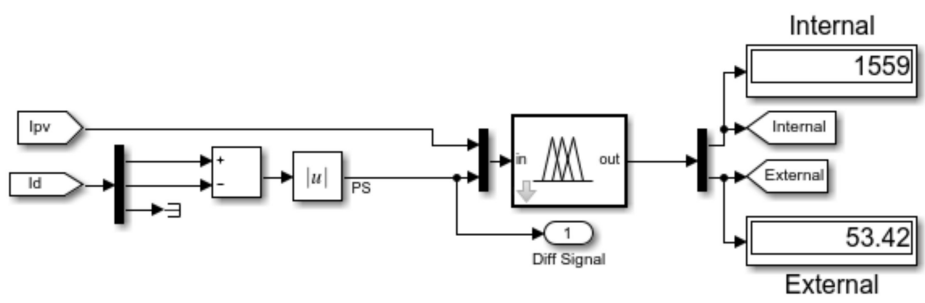

Figure 13. The internal and external crisp value under $1.6 \%$ TTF condition. 
Three of the sub algorithms were internal faults, and one was a normal condition at $1.6 \%$ short turns level. At the $0.8 \%$ short turns level, two sub algorithms were internal faults, and another was normal condition. Hence, the hybrid detection algorithm set an internal fault as the final decision for both levels. Four sub algorithms were declared as an internal fault when the turn-to-turn level reached $2.4 \%$. The hybrid detection algorithm decided to set an internal fault as the result. In this case, the hybrid algorithm overcame wrong decisions from several sub algorithms and gave a correct result. The internal fault condition was declared as the result by the hybrid detection algorithm based on the sub algorithm result (see Figure 14). The summary of the results of the experiment is shown in Figure 15.

HYBRID PROTECTION ALGORITHM

\begin{tabular}{|c|c|c|c|}
\hline Methode: & & & \\
\hline 1. Conventional Diff Protection & Fault & \multicolumn{2}{|c|}{ Normal } \\
\hline 2. Diff Negative Squence Protection & Internal Fault & \multicolumn{2}{|c|}{ Non-Internal Fault } \\
\hline $\begin{array}{l}\text { 3. Extended Park Vector Algorithm } \\
\text { (EPVA) Protection }\end{array}$ & Internal Fault & \multicolumn{2}{|c|}{ Non-Internal Fault } \\
\hline $\begin{array}{l}\text { 4. Negative Sequence Directional } \\
\text { Algorithm Protection }\end{array}$ & Internal Fault & External Fault & Normal \\
\hline 5. Fuzzy Protection & Internal Fault & External Fault & Normal \\
\hline $\begin{array}{l}\text { H Y B R I D C OMB INAT I ON } \\
\text { RESULT }\end{array}$ & Internal Fault & External Fault & Normal \\
\hline
\end{tabular}

Figure 14. The hybrid algorithm result under the TTF scheme.

\begin{tabular}{|c|c|c|}
\hline Subalgorithm & Decision & Description \\
\hline \multirow{2}{*}{$\begin{array}{l}\text { Conventional Diff } \\
\text { Protection }\end{array}$} & Normal Condition & TTF level : $0.8-6.7 \%$ \\
\hline & Fault Conditon & TTF level : $7.5-16.3 \%$ \\
\hline \multirow{3}{*}{$\begin{array}{c}\text { Negative Directional } \\
\text { Algorithm }\end{array}$} & Normal Condition & TTF Level: $0.8-1.6 \%$ \\
\hline & Intenal fault Conditon & TTF Level: 2.4 - 12.3\% \\
\hline & External Fault Conditon & TTF Level: 13.1 - 16.3\% \\
\hline \multirow{2}{*}{$\begin{array}{c}\text { Differential Negative } \\
\text { Sequence }\end{array}$} & Internal Fault Condition & TTF Level:0.8 - 16.3\% \\
\hline & Non-internal Fault Condition & - \\
\hline \multirow{2}{*}{$\begin{array}{c}\text { Extended Park Vector } \\
\text { Algorithm }\end{array}$} & Internal Fault Condition & TTF Level:0.8 - 16.3\% \\
\hline & Non-internal Fault Condition & _ \\
\hline \multirow{3}{*}{ Fuzzy } & Normal Condition & TTF Level: $0.8 \%$ \\
\hline & Intenal fault Conditon & TTF Level: 1.6 - 16.3\% \\
\hline & External Fault Conditon & _ \\
\hline \multicolumn{3}{|c|}{ Final Decision } \\
\hline \multirow{3}{*}{$\begin{array}{c}\text { HYBRID } \\
\text { COMBINATION } \\
\text { RESULT }\end{array}$} & Normal Condition & \\
\hline & Intenal fault Conditon & TTF Level:0.8 - 16.3\% \\
\hline & External Fault Conditon & \\
\hline
\end{tabular}

Figure 15. Summary of the results from the TTF scheme with different level short turn. 


\subsection{External Fault Scheme}

In this scheme, the external fault happened at $t=3 \mathrm{~s}$ in the secondary side phase A. The external fault was simulated with a short line between the line-to-line and lineto-ground in the secondary side. The resistor was used to mimic the short circuit in the simulation, with several values $(50,100,500,600,700$, and $800 \mathrm{ohms})$. The external fault condition created a massive differential current. The primary and secondary current on the terminal voltage (see in Figure 16) showed a significant difference before and after the fault. The conventional differential protection detected the external fault because the differential current between the primary and secondary sides exceeded the limit as shown in Figure 17. The phase difference between the primary and secondary negative sequence current also stayed above $85^{\circ}$. The external fault scheme, the negative sequence current from the primary (Ip2) and secondary (Is2) side, rose significantly. The phase difference between both sides stabilized at $118^{\circ}$ (see in Figure 18). Based on that, the directional algorithm was declared an external fault condition.
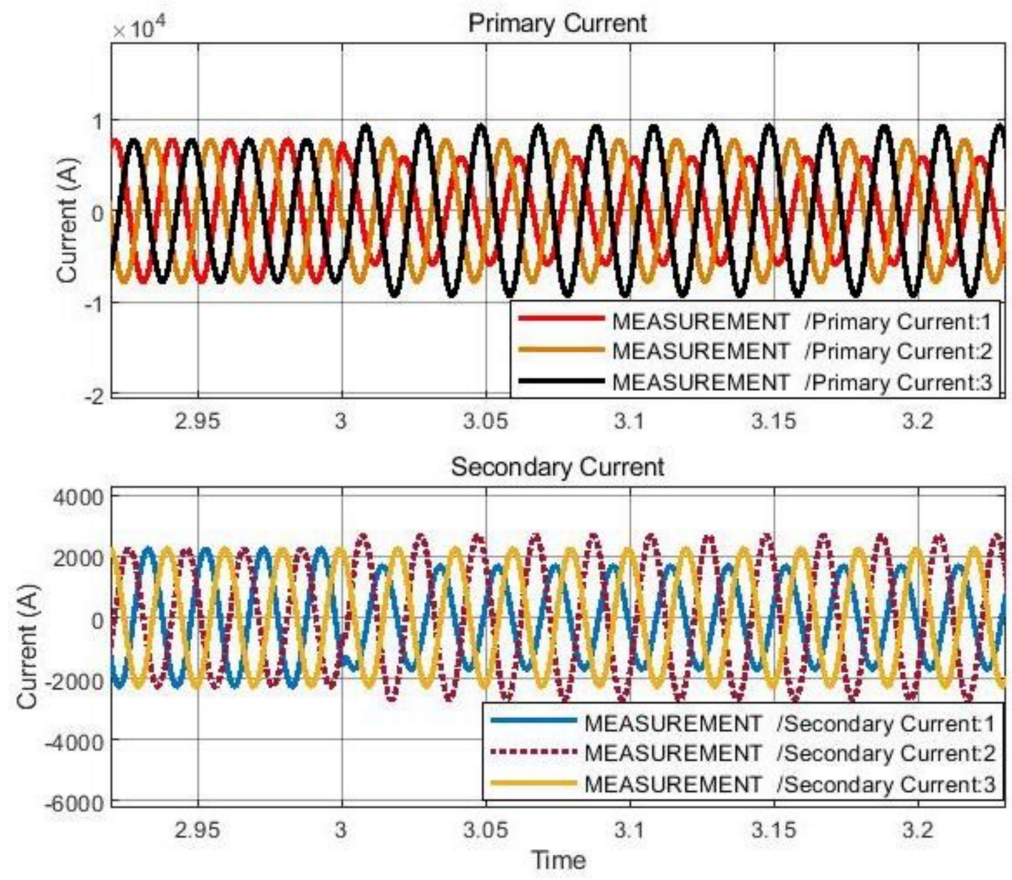

Figure 16. The fundamental signal under the external fault.

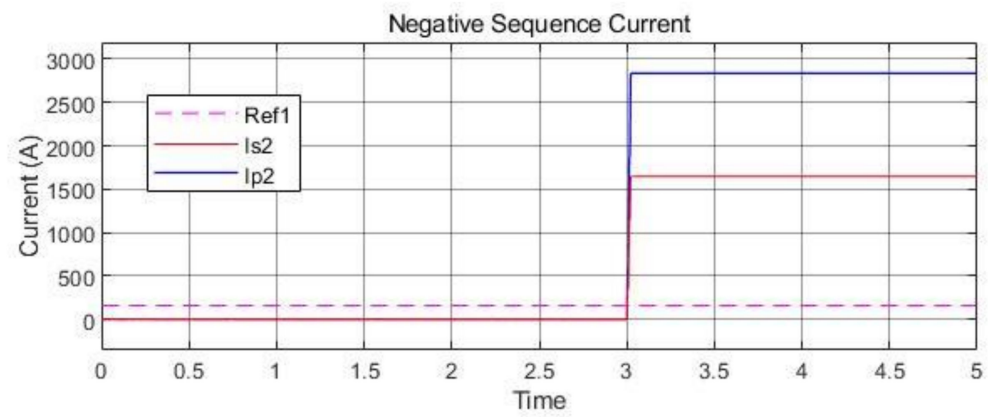

Figure 17. The negative sequence current from the primary and secondary side under an external fault. 


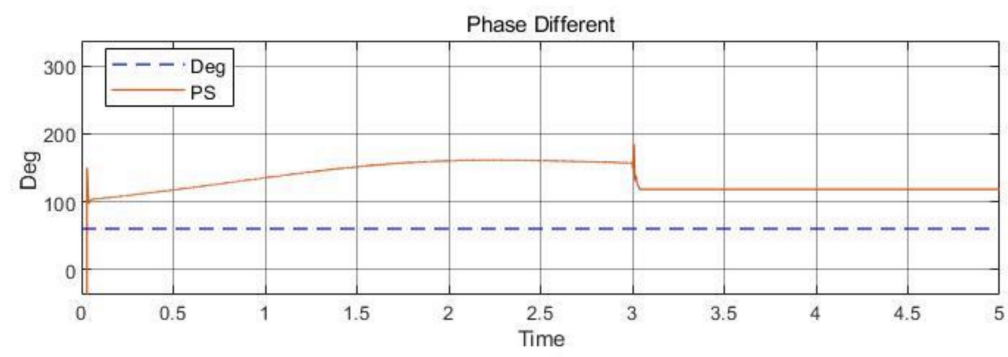

Figure 18. The phase difference between Ip2 and Is2 under an external fault.

The EPVA and differential negative-sequence algorithm were unable to distinguish between a normal and an external fault. When an external fault happened, $i_{\text {epva, }}$ the differential negative sequence current did not increase or exceed the threshold value. Therefore, the transformer condition was declared as a non-internal fault. However, this condition also occurred at normal conditions, as shown in Figures 19 and 20. The fuzzy algorithm generated a crisp external value more significant than the crisp internal value. The internal and external fault crisp values were 15.26 and 7918, respectively like shown in Figure 21. Therefore, the fuzzy algorithm generated the external fault status.

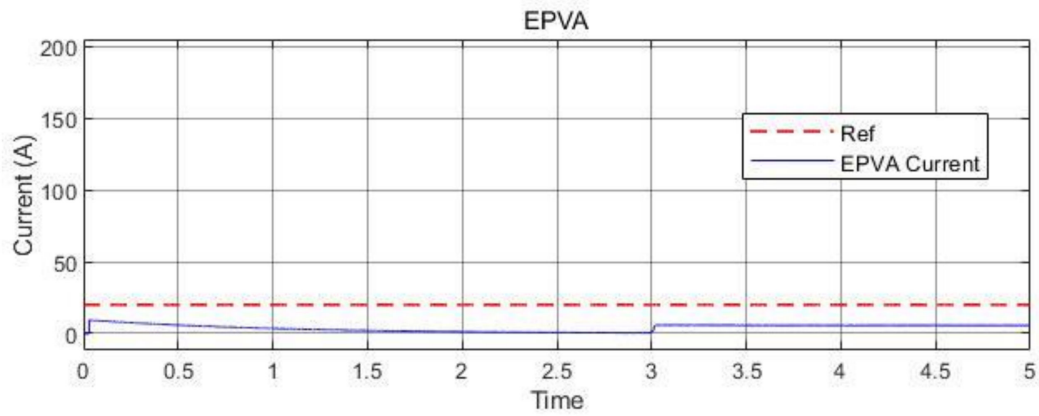

Figure 19. $i_{\text {epva }}$ under an external fault.

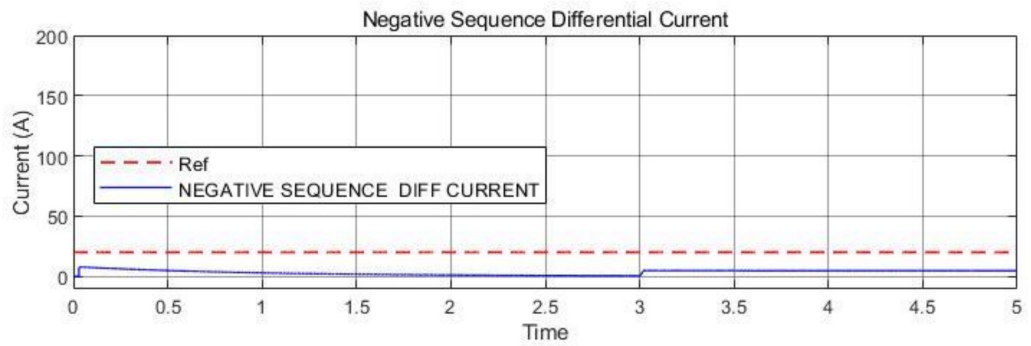

Figure 20. The differential negative sequence current under an external fault.

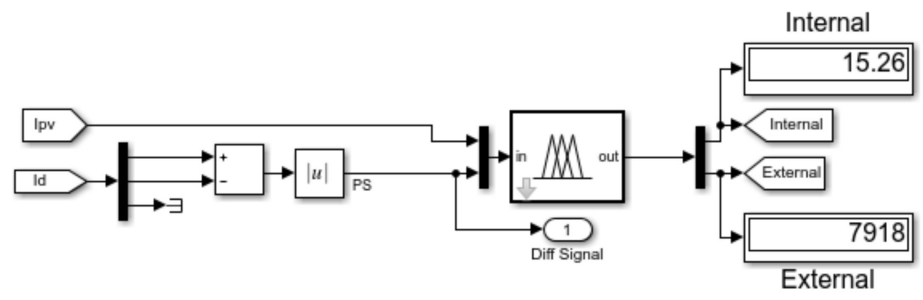

Figure 21. The internal and external crisp value under an external fault. 
This limitation can be overcome by the negative-sequence directional algorithm, conventional differential protection, and fuzzy algorithm, where three sub algorithms detect the external fault. Therefore, the hybrid detection algorithm chooses an external fault as the result. The hybrid detection algorithm generated the correct result about the transformer condition in the external fault scheme (see in Figure 22). The summary of the results is shown as either the sub algorithms or the hybrid algorithm that declared the external fault status at the PT (see in Figure 23).

\begin{tabular}{|c|c|c|c|}
\hline \multicolumn{4}{|l|}{ Methode: } \\
\hline 1. Conventional Diff Protection & Fault & \multicolumn{2}{|c|}{ Normal } \\
\hline 2. Diff Negative Squence Protection & Internal Fault & \multicolumn{2}{|c|}{ Non-Internal Fault } \\
\hline $\begin{array}{l}\text { 3. Extended Park Vector Algorithm } \\
\text { (EPVA) Protection }\end{array}$ & Internal Fault & \multicolumn{2}{|c|}{ Non-Internal Fault } \\
\hline $\begin{array}{l}\text { 4. Negative Sequence Directional } \\
\text { Algorithm Protection }\end{array}$ & Internal Fault & External Fault & Normal \\
\hline 5. Fuzzy Protection & Internal Fault & External Fault & Normal \\
\hline $\begin{array}{l}\text { H Y B R I D COM B I NAT I ON } \\
\text { RES ULT }\end{array}$ & Internal Fault & External Fault & Normal \\
\hline
\end{tabular}

Figure 22. The hybrid algorithm result in the external fault scheme.

\begin{tabular}{|c|c|c|}
\hline Subalgorithm & Decision & Description \\
\hline \multirow[b]{2}{*}{$\begin{array}{l}\text { Conventional Diff } \\
\text { Protection }\end{array}$} & Normal Condition & _- \\
\hline & Fault Conditon & $\begin{array}{l}\text { All short location with } \\
\text { variaton of short } \\
\text { resistant value }\end{array}$ \\
\hline \multirow{3}{*}{$\begin{array}{l}\text { Negative Directional } \\
\text { Algorithm }\end{array}$} & Normal Condition & \\
\hline & Intenal fault Conditon & \\
\hline & External Fault Conditon & $\begin{array}{l}\text { All short location with } \\
\text { variaton of short } \\
\text { resistant value }\end{array}$ \\
\hline \multirow[b]{2}{*}{$\begin{array}{l}\text { Differential Negative } \\
\text { Sequence }\end{array}$} & Internal Fault Condition & \\
\hline & Non-internal Fault Condition & $\begin{array}{l}\text { All short location with } \\
\text { variaton of short } \\
\text { resistant value }\end{array}$ \\
\hline \multirow[b]{2}{*}{$\begin{array}{c}\text { Extended Park Vector } \\
\text { Algorithm }\end{array}$} & Internal Fault Condition & \\
\hline & Non-internal Fault Condition & $\begin{array}{l}\text { All short location with } \\
\text { variaton of short } \\
\text { resistant value }\end{array}$ \\
\hline \multirow[b]{3}{*}{ Fuzzy } & Normal Condition & \\
\hline & Intenal fault Conditon & \\
\hline & External Fault Conditon & $\begin{array}{l}\text { All short location with } \\
\text { variaton of short } \\
\text { resistant value }\end{array}$ \\
\hline \multicolumn{3}{|c|}{ Final Decision } \\
\hline \multirow{3}{*}{$\begin{array}{l}\text { HYBRID COMBINATION } \\
\text { RESULT }\end{array}$} & Normal Condition & \\
\hline & Intenal fault Conditon & \\
\hline & External Fault Conditon & $\begin{array}{l}\text { All short location with } \\
\text { variaton of short } \\
\text { resistant value }\end{array}$ \\
\hline
\end{tabular}

Figure 23. A summary of the results from the external fault scheme. 


\subsection{Normal Scheme}

In this scheme, we simulated a normal transformer condition with a variation in the load. This scheme aimed to ensure the protection of the algorithm to generate correct results in a normal condition. The summary result (see Figure 24) showed that the hybrid detection algorithm was declared a normal state in a normal scheme. All sub algorithm and hybrid algorithm declared non internal fault or normal status like shown in Figure 25. Using the hybrid detection algorithm increases accuracy more than using a single algorithm (see Figure 26). The fuzzy algorithm generated the sub algorithm's highest accuracy, $98 \%$, when distinguishing between a fault and normal condition (accuracy one). Accuracy two distinguished between the internal and non-internal fault. The highest accuracy of the sub algorithm occurred in the differential negative sequence and EPVA. Accuracy three distinguished between internal, external, and normal conditions, where the highest accuracy of the sub algorithm occurred on the fuzzy algorithm. The fuzzy algorithm was useful in detecting the fault and distinguishing between an internal or external fault. Additionally, using the fuzzy algorithm requires the experience to design the inference rule and membership function for input or output, where the design can be different for other types of transformers. However, a hybrid detection algorithm can overcome the misdetection of the fuzzy algorithm and increase fault detection accuracy.

\begin{tabular}{|c|c|c|}
\hline Subalgorithm & Decision & Description \\
\hline \multirow{2}{*}{$\begin{array}{l}\text { Conventional Diff } \\
\text { Protection }\end{array}$} & Normal Condition & $\begin{array}{l}\text { in all normal conditon } \\
\text { with variation of load }\end{array}$ \\
\hline & Fault Conditon & \\
\hline \multirow{3}{*}{$\begin{array}{l}\text { Negative Directional } \\
\text { Algorithm }\end{array}$} & Normal Condition & $\begin{array}{l}\text { in all normal conditon } \\
\text { with variation of load }\end{array}$ \\
\hline & Intenal fault Conditon & \\
\hline & External Fault Conditon & \\
\hline \multirow{2}{*}{$\begin{array}{c}\text { Differential Negative } \\
\text { Sequence }\end{array}$} & Internal Fault Condition & \\
\hline & Non-internal Fault Condition & $\begin{array}{l}\text { in all normal conditon } \\
\text { with variation of load }\end{array}$ \\
\hline \multirow{2}{*}{$\begin{array}{c}\text { Extended Park Vector } \\
\text { Algorithm }\end{array}$} & Internal Fault Condition & \\
\hline & Non-internal Fault Condition & $\begin{array}{l}\text { in all normal conditon } \\
\text { with variation of load }\end{array}$ \\
\hline \multirow{3}{*}{ Fuzzy } & Normal Condition & $\begin{array}{l}\text { in all normal conditon } \\
\text { with variation of load }\end{array}$ \\
\hline & Intenal fault Conditon & \\
\hline & External Fault Conditon & \\
\hline \multicolumn{3}{|c|}{ Final Decision } \\
\hline \multirow{3}{*}{$\begin{array}{c}\text { HYBRID COMBINATION } \\
\text { RESULT }\end{array}$} & Normal Condition & $\begin{array}{l}\text { in all normal conditon } \\
\text { with variation of load }\end{array}$ \\
\hline & Intenal fault Conditon & \\
\hline & External Fault Conditon & \\
\hline
\end{tabular}

Figure 24. A summary of the results from the normal scheme.

\begin{tabular}{|c|c|c|c|}
\hline Methode: & & & \\
\hline Conventional Diff Protection & Fault & \multicolumn{2}{|c|}{ Normal } \\
\hline Diff Negative Squence Protection & Internal Fault & \multicolumn{2}{|c|}{ Non-Internal Fault } \\
\hline $\begin{array}{l}\text { Extended Park Vector Algorithm } \\
\text { (EPVA) Protection }\end{array}$ & Internal Fault & \multicolumn{2}{|c|}{ Non-Internal Fault } \\
\hline $\begin{array}{l}\text { Negative Sequence Directional } \\
\text { Algorithm Protection }\end{array}$ & Internal Fault & External Fault & Normal \\
\hline Fuzzy Protection & Internal Fault & External Fault & Normal \\
\hline $\begin{array}{l}\text { IYBRID COMBINATION } \\
\text { R SULT }\end{array}$ & Internal Fault & External Fault & Normal \\
\hline
\end{tabular}

Figure 25. The hybrid algorithm results from the normal scheme. 


\begin{tabular}{|c|c|c|c|}
\hline & $\begin{array}{c}\text { Accuracy } 1 \\
\text { (Fault or } \\
\text { Normal } \\
\text { Condition): }\end{array}$ & $\begin{array}{l}\text { Accuracy } 2 \\
\text { (Internal or } \\
\text { Non - internal } \\
\text { Fault): }\end{array}$ & $\begin{array}{l}\text { Accuracy } 3 \\
\text { (Internal, } \\
\text { External, and } \\
\text { Normal): }\end{array}$ \\
\hline $\begin{array}{l}\text { Conventional Diff } \\
\text { Protection }\end{array}$ & $84 \%$ & $84 \%$ & $84 \%$ \\
\hline $\begin{array}{c}\text { Negative Directional } \\
\text { Algorithm }\end{array}$ & $96 \%$ & $91 \%$ & $91 \%$ \\
\hline $\begin{array}{l}\text { Differential Negative } \\
\text { Sequence }\end{array}$ & $63 \%$ & $100 \%$ & $78 \%$ \\
\hline $\begin{array}{c}\text { Extended Park Vector } \\
\text { Algorithm }\end{array}$ & $63 \%$ & $100 \%$ & $78 \%$ \\
\hline Fuzzy & $98 \%$ & $98 \%$ & $98 \%$ \\
\hline $\begin{array}{c}\text { HYBRID COMBINATION } \\
\text { RESULT }\end{array}$ & $100 \%$ & $100 \%$ & $100 \%$ \\
\hline
\end{tabular}

Figure 26. A summary of accuracy results.

\section{Conclusions}

The hybrid algorithm protection's objective is to minimize the misdiagnosis status generated by each sub algorithm regarding a $\mathrm{PT}^{\prime}$ 's condition. The algorithm declares a fault condition based on the results from the sub algorithms. The algorithm's application is safe and simple and will not change the existing electrical system since its output is not connected to any circuit breaker protection. Based on the simulation result, the hybrid algorithm can detect incipient TTF until the $0.8 \%$ short-turn level, and increase the accuracy of TTF detection. In our simulation results for the TTF case, the hybrid algorithm detected the internal fault case in all the short-turn levels.

In this research, we only applied our proposed algorithm to a three-phase PT using a MATLAB Simulink model and a terminal current signal as an input. Hence, external factors such as temperature inside the PT, oil pressure, and other environmental aspects were not considered as an input for our system. Referring to the limitation issue, future research is needed to improve the methods for protecting PT.

Author Contributions: Conceptualization, methodology, W.H.P.M., software and validation, W.H.P.M.; formal analysis, W.H.P.M., and C.-H.L.; writing—review and editing, W.H.P.M. and C.-H.L.; supervision, C.-C.K. All authors have read and agreed to the published version of the manuscript.

Funding: This researched receive no external funding.

Institutional Review Board Statement: Not applicable.

Informed Consent Statement: Not applicable.

Data Availability Statement: Not applicable.

Conflicts of Interest: The authors declare no conflict of interest.

\section{References}

1. Liu, Y.; Song, B.; Wang, L.; Gao, J.; Xu, R. Power Transformer Fault Diagnosis Based on Dissolved Gas Analysis by Correlation Coefficient-DBSCAN. Appl. Sci. 2020, 10, 4440. [CrossRef]

2. Shah, A.M.; Bhalja, B.R. Fault discrimination scheme for power transformer using random forest technique. IET Gener. Transm. Distrib. 2016, 10, 1431-1439. [CrossRef]

3. Oliveira, L.M.R.; Cardoso, A.J.M. Power transformers behavior under the occurrence of inrush currents and turn-to-turn winding insulation faults. In Proceedings of the XIX International Conference on Electrical Machines-ICEM 2010, Rome, Italy, 6-8 September 2010; pp. 1-7. 
4. Ramesh, K.; Sushama, M. Inter-turn fault detection in power transformer using fuzzy logic. In Proceedings of the 2014 International Conference on Science Engineering and Management Research (ICSEMR), Chennai, India, 27-29 November 2014; pp. 1-5.

5. Geißler, D.H. Short-Circuit Withstand Capability of Power Transformers; Cuvillier Verlag: Göttingen, Germany, 2015.

6. Gouda, O.E.; Dein, A.Z.E.; Moukhtar, I. Turn-to-earth fault modelling of power transformer based on symmetrical components. IET Gener. Transm. Distrib. 2013, 7, 709-716. [CrossRef]

7. Kasztenny, B.; Thompson, M.; Fischer, N. Fundamentals of short-circuit protection for transformers. In Proceedings of the 2010 63rd Annual Conference for Protective Relay Engineers, College Station, TX, USA, 29 March-1 April 2010; pp. 1-13.

8. Shah, A.M.; Bhalja, B.R.; Patel, R.M. New protection scheme for power transformer based on superimposed differential current. IET Gener. Transm. Distrib. 2018, 12, 3587-3595. [CrossRef]

9. Sahebi, A.; Samet, H. Efficient method for discrimination between inrush current and internal faults in power transformers based on the non-saturation zone. IET Gener. Transm. Distrib. 2017, 11, 1486-1493. [CrossRef]

10. Oliveira, L.M.R.; Cardoso, A.J.M. Comparing Power Transformer Turn-to-Turn Faults Protection Methods: Negative Sequence Component Versus Space-Vector Algorithms. IEEE Trans. Ind. Appl. 2017, 53, 2817-2825. [CrossRef]

11. Subramanian, S.; Padma, S. Bacterial Foraging Algorithm based Parameter Estimation of Three WINDING Transformer. Energy Power Eng. 2011, 3, 135-143. [CrossRef]

12. Li, H.; Yang, D.; Ren, Z.; Li, Z. Based on PSO-BP network algorithm for fault diagnosis of power transformer. In Proceedings of the 2010 International Conference on Computer, Mechatronics, Control and Electronic Engineering, Changchun, China, 24-26 August 2010; pp. 484-487.

13. Abdelwanis, M.I.; Abaza, A.; El-Sehiemy, R.A.; Ibrahim, M.N.; Rezk, H. Parameter Estimation of Electric Power Transformers Using Coyote Optimization Algorithm With Experimental Verification. IEEE Access 2020, 8, 50036-50044. [CrossRef]

14. Yilmaz Acar, Z.; Oksar, M.; Basciftci, F. Multi-Objective Artificial Bee Colony Algorithm to Estimate Transformer Equivalent Circuit Parameters. Period. Eng. Nat. Sci. 2017, 5, 271-277. [CrossRef]

15. Sarkhanloo, M.S.; Ghalledar, D.; Azizian, M.R. Diagnosis of stator winding turn to turn fault of induction motor using space vector pattern based on neural network. In Proceedings of the 3rd Conference on Thermal Power Plants, Tehran, Iran, 18-19 October 2011; pp. 1-6.

16. Faridi, M.; Rahimpour, E.; Kharezi, M.; Mirzaei, H.R.; Akbari, A. Localization of turn-to-turn fault in transformers using Artificial Neural Networks and winding transfer function. In Proceedings of the 10th IEEE International Conference on Solid Dielectrics, Potsdam, Germany, 4-9 July 2010; pp. 1-6.

17. Ouyang, F.; Liu, Y.; Liang, Z.; Qiu, Z.; Yuan, B. Parameter identification of transformer based on PSO algorithm. In Proceedings of the 2018 International Conference on Power System Technology (POWERCON), Guanzhou, China, 6-9 November 2018; pp. 3864-3870.

18. Myong-Chul, S.; Chul-Won, P.; Jong-Hyung, K. Fuzzy logic-based relaying for large power transformer protection. IEEE Trans. Power Deliv. 2003, 18, 718-724. [CrossRef]

19. Li, X.; Zhou, L.; Tong, X.; Chen, M. Fault Diagnosis of Power Transformer Insulation Based on Fuzzy Normal Partition and Logic Reasoning. In Proceedings of the 2007 International Conference on Machine Learning and Cybernetics, Hong Kong, China, 19-22 August 2007; pp. 1081-1085.

20. Barbosa, D.; Netto, U.C.; Coury, D.V.; Oleskovicz, M. Power Transformer Differential Protection Based on Clarkes Transform and Fuzzy Systems. IEEE Trans. Power Deliv. 2011, 26, 1212-1220. [CrossRef]

21. Ouahdi, R.; Elmareimi, M.F.; Fouad, R. Transformer Differential Protection Scheme with Internal Faults Detection Algorithm Using Second Harmonics Restrain and Fifth Harmonics Blocking Logic. Available online: https://www.semanticscholar.org/ paper/TRANSFORMER-DIFFERENTIAL-PROTECTION-SCHEME-WITH-AND-Elmareimi-Fouad/0c8a141c8d3146dd22ae1 9011e19521d880c0220\#citing-papers (accessed on 13 March 2021).

22. Babiy, M.; Gokaraju, R.; Garcia, J.C. Turn-to-turn fault detection in transformers using negative sequence currents. In Proceedings of the 2011 IEEE Electrical Power and Energy Conference, Winnipeg, MB, Canada, 3-5 October 2011; pp. 158-163.

23. Zacharias, D.; Gokaraju, R. Prototype of a Negative-Sequence Turn-to-Turn Fault Detection Scheme for Transformers. IEEE Trans. Power Deliv. 2016, 31, 122-129. [CrossRef]

24. Guerreiro, M.; Pires, V.F. A Transformer Differential Relay Based on a Multiple Park Transformation. In Proceedings of the 2007 International Conference on Power Engineering, Energy and Electrical Drives, Setubal, Portugal, 12-14 April 2007; pp. 400-404.

25. Oliveira, L.; Cardoso, A.J.M. Extended Parks vector approach-based differential protection of three-phase power transformers. IET Electr. Power Appl. 2012, 6, 463-472. [CrossRef]

26. Lilly, J.H. Fuzzy Control and Identification; John Wiley \& Sons, Inc.: Hoboken, NJ, USA, 1949. 